\title{
Measurement of Information System Project Success Based on Perceptions of the Internal Stakeholders
}

\author{
A’ang Subiyakto*, Abd. Rahman Ahlan**, Mira Kartiwi**, Husni Teja Sukmana*** \\ * Department of Information System, Syarif Hidayatullah State Islamic University, Jakarta, Indonesia \\ ** Department of Information System, International Islamic University Malaysia, Kuala Lumpur, Malaysia \\ *** Department of Informatics Engineering, Syarif Hidayatullah State Islamic University, Jakarta, Indonesia
}

\section{Article Info}

Article history:

Received Dec 10, 2014

Revised Feb 9, 2015

Accepted Feb 17, 2015

\section{Keyword:}

D\&M model

Information system

PLS-SEM

Project success

Survey

\begin{abstract}
In this research, adoption of the DeLone and McLean (D\&M) information system (IS) success model and its adaptation with the project success theories were used to explore state of an IS project success and to examine factors which affect the success. A survey towards the internal project stakeholders in a university was carried out with a response rate of $48 \%(n=62)$. Partial least squares-structural equation modelling (PLS-SEM) analysis then was applied because of the sample size. Majority respondents $(80.7 \%)$ represented that the success level is more than $50 \%$ where information quality, system quality, service quality, system use, and user satisfaction substantially explain $58.8 \%$ of variance in the success variable. Although, a numeral of the findings was reproducible with the prior studies, these findings also presented inconsistencies, particularly connected to aspects of information quality and organization utilization. Consequently, researchers and practitioners will remain firm to profit from the data catered in this study and it is hoped that future research will establish upon the findings described herein as efforts are pulled in to make the IS project success particularly in the sampled institution.
\end{abstract}

Copyright (C) 2015 Institute of Advanced Engineering and Science. All rights reserved.

\section{Corresponding Author:}

A'ang Subiyakto,

Department of Information System, Syarif Hidayatullah State Islamic University Jakarta,

Jl. Ir. H, Juanda No. 95, Tangerang, 15412, Indonesia.

Email: aang_subiyakto@uinjkt.ac.id

\section{INTRODUCTION}

Nowadays, it is hard to refute that IS is an enabler $[1,2]$ in reinforcing and improving business of the users, but firstly, they must successfully develop their systems to get the benefits [3]. This means that the success of the projects will be the first challenge for the users [3]. Meanwhile, some researchers, e.g. [4] warned that the project failures can cause substantial financial losses to the project owners and even jeopardize their survival. This has been an interesting issue for researchers and practitioners since many years ago especially after the Standish Group published their first survey findings in 1994 [6]. Accordingly, many scholars, e.g. [7] who proposed D\&M IS success model in 1992, had been trying to respond to this issue in order to raise the project success level. Researchers [8-10] mentioned that the model has been the predominant basis of IS success measurement over two last decades, only they too concluded that the wide popularity of this model is also strong indication of the demand for its utilization in the further success measurement studies in the context for carrying out and developing the good example. Specifically, [8] suggested both researchers and practitioners to use the overall dimensions of the model in order to present the whole portrait of processional model. Similarly, [8-10] found that most scholars who have utilized this model to date, have only focused on utilization of the selected parts of the model, which could affect the overall validity of their system measurements. Therefore, these scholars [8-10] suggested researchers and practitioners to use the complete model to gain the overall measurement validity. 
In this study, we drew heavily from the D\&M IS success model [7] and integrated it with processional and causal concepts from selected project success theories [11-14] in order to measure an IS project success. This modelling approach is in line with [15] who mentioned that numerous models are developed based on the previous theories rather than on empirical proofs. This study was performed in order to explore the state of IS project success in Syarif Hidayatullah State Islamic University (Universitas Islam Negeri [UIN]) Jakarta and examine whether constructs that affected the project in particular from perceptions of the internal project stakeholders. Similar to the work of $\mathrm{Xu}$ et al. [5], the term IS in this study was used interchangeably with information technology (IT) and information and communication technology (ICT) referring to a system which was used to deploy business processes and its services. A survey was carried out on as a sample of 130 IS project stakeholders who have been involved in IS projects with 62 (48\%) usable questionnaires returned. Considering the small size of the sample, an SEM-PLS analysis was performed on the data. The study addresses two research questions: (1) How is the level of success the current IS project? (2) What are the factors that affect the IS project success?

The paper is organized as follows. In the second section, we summarize the insights of the literature on project success theories and the D\&M IS success model in order to develop the proposed hypotheses. We then describe the research method in the third section and present the analysis results in the fourth section. In the fifth section, we discuss the results from the theoretical and practical perspectives and address limitations of this study as well as adding suggestions for possible the future research. In the last section, we provide overall summary and conclusion of the whole study.

\section{THEORETICAL FRAMEWORK AND HYPOTHESES DEVELOPMENT}

Concepts of the project success have been discoursing among researchers and practitioners for many years [14-17] especially for determining what the success definition is. The definition has been changed over times, discussed oftentimes, and still lack of agreement, particularly for which criteria will have used [14-17]. De Wit [11] mentioned that "The most appropriate criteria for success are the project's objectives. The degrees to which these objectives have been met determine the success of the project." He also indicated consideration of the project management and product success separations, as it then was defined clearly by [12] that project success is a combination of project management success and product success. In addition, [13] enriched this definition and mentioned that "the satisfaction of all stakeholders" as his project success definition. Retrospectively, [14] then concluded that project success connotes with different things to different people, and very context-dependent. Based on the above mentioned literatures, we conclude that the success of a project can be measured through processional and causal reviews of the project performance from the project management and the product utilization dimensions with considering the perspectives of the stakeholders [12-17]. On the other hand, three prior meta-analysis studies [8-10] indicated that many IS researchers have been used D\&M IS success model [7] for over two decades and suggested to use the complete model for reaching the overall validity of the measurement. The authors [7] described that the model was developed based on the communication research [18] and the information "influence" theory [19] into three components: the creation of a system, the use of the system, and the consequences (impact) of this system.

Accordingly, we adopted the overall model [7] and adapted the logical sense in line with the project success theories [11-14] in the context of an IS project success measurement (Figure 1). We assumpt the system creation is a project management success. The system uses the product utilization success, and the system impact as the project success. Considering the previous three meta analysis studies [8-10], we proposed 13 hypotheses in regard to above mentioned issues:

H1a: Information Quality (INQ) affects significantly System Use (SYU);

H1b: Information Quality (INQ) affects significantly User Satisfaction (USF);

H1c: Information Quality (INQ) affects significantly IS Project Success (PSC);

H2a: System Quality (SYQ) affects significantly System Use (SYU);

H2b: System Quality (SYQ) affects significantly User Satisfaction (USF);

H2c: System Quality (SYQ) affects significantly IS Project Success (PSC);

H3a: Service Quality (SVQ) affects significantly System Use (SYU);

H3b: Service Quality (SVQ) affects significantly User Satisfaction (USF);

H3c: Service Quality (SVQ) affects significantly IS Project Success (PSC);

H4a: System Use (SYU) affects significantly User Satisfaction (USF);

H4b: System Use (SYU) affects significantly IS Project Success (PSC);

H5: User Satisfaction (USF) affects significantly IS Project Success (PSC). 


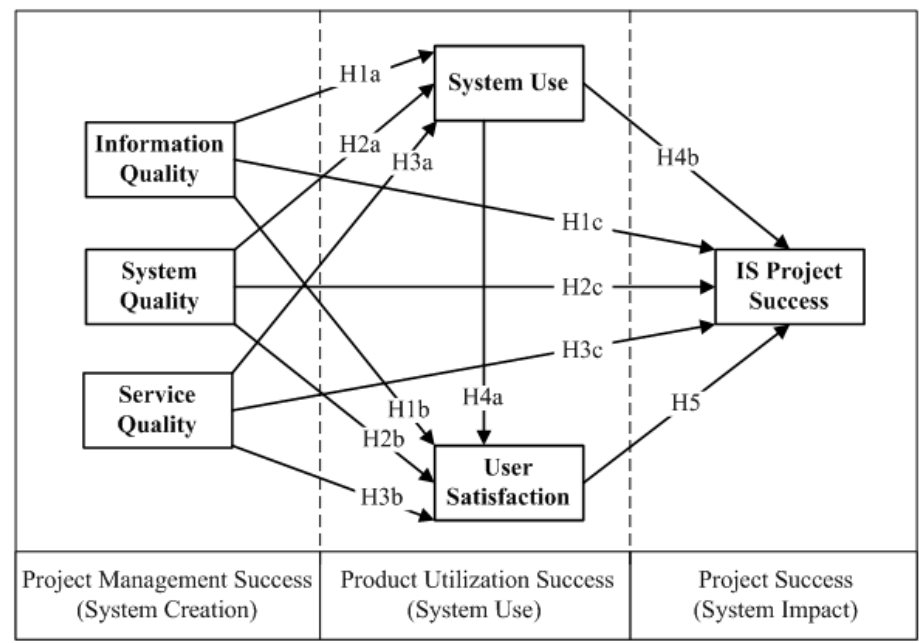

Figure 1. The proposed model (Adapted from [7-14])

\section{RESEARCH METHOD}

Figure 2 presents the eight stages of this study, which has been performed during January to October 2014. The population was 212 internal project stakeholders of the IS project, i.e. top managers, business unit managers, IS/IT unit managers, project managers, and project team members. The data were received from the personnel administration unit of the sampled institution. Referred to the key informant point [20-21], we randomly selected $130(49 \%)$ respondents who experienced in the projects and then sent 90 on-line questionnaires and 40 paper-based questionnaires. 62 of $130(48 \%)$ respondents participated in the survey, including $39(30 \%)$ electronic and $23(18 \%)$ paper-based versions. The collected raw data then were processed using MS. Excel 2007 and converted into .csv file format using SPSS version 20 as input file for SmartPLS 2.0 analysis. Table 1 presents the demographic information of the respondents.

Instruments of the study were survey questionnaires including invitation letter, introduction, and question pages with a link to the electronic version. The question items included 3 respondent profile, 6 project profile, and 29 examination questions. The measurement items were anchored on a 5-point Likert scale ranging from "strongly disagree" to "strongly agree" [22] in which respondents were asked to indicate the appropriate response. In order to ensure validity of this instrument, we adopted a number of validated sourcesquestions from the previous research works (Table 3), performed pre-test to receive empirical feedback from five academicians who experienced and skilled in IS/IT researches, and assessed the measurement model [31-36] with the four indicator deletions (SVQ6, SYQ2, USF1, and PCS5) because of unreliabilities or invalidities of the indicators (Table 3 ).

In the analysis stage, PLS-SEM with SmartPLS 2.0 was considered to be used because the small size of the sample with $n=62$ [31-36]. The descriptive analysis was performed to present profiles of the respondents (Table 1) and to capture profile of the project performance, especially in order to answer the first research question (Table 2). Meanwhile, the inferential analysis was performed to examine the formulated hypotheses. Specifically, the measurement model assessments were conducted reflectively to evaluate the validity and reliability of the variables and their indicators using indicator reliability, internal consistency reliability, convergent validity, and discriminant validity assessments [33-36]. Furthermore, the structural model assessments were carried out to evaluate the coefficient of determination $\left(R^{2}\right)$ of the endogenous latent variables, the path coefficients $(\beta)$, the effect size $\left(f^{2}\right)$, and the structural path significance via bootstrapping to validate the hypotheses [33-36].

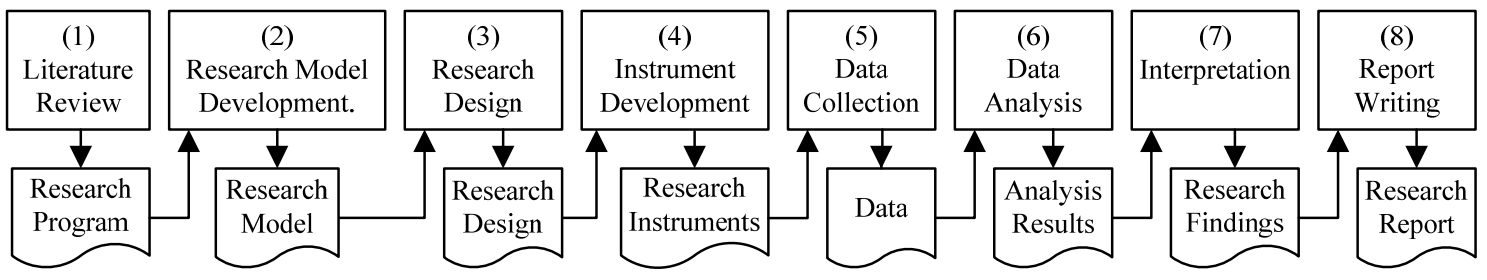

Figure 2. The research procedure 


\section{RESULTS AND ANALYSES}

The descriptive analysis presented the demographic information of the respondents (Table 1) and the IS project state (Table 2). All of the respondents were educated with the majority of the respondents $(91.9 \%)$ graduated bachelor and above, especially the master degrees which were the highest percentage $(56.5 \%)$. Distribution of IS project experience shows that, most of the respondents $(91.9 \%)$ have been experienced under 10 years on the project and most of them (40.3\%) have been experienced during 5-10 years. Moreover, the highest percentage of the respondents $(58.1 \%)$ was the project team members. In addition, there are five main descriptions of the project state. 1) Most of the respondents (41.9\%) indicated that the development goals of the project were to fulfil operational requirements. 2) The majority of them stated (71\%) that their institution has the IS strategic plan. 3) The IS development project was performed majority by internal personnels $(43.5 \%)$. 4) In the project funding points, the highest percentage of the respondents (38.7\%) answered that the project was funded majority by internal funding. On the other hand, the lowest percentage (4.8\%) answered the project was funded $100 \%$ by external funding. 5) Majority of the respondents $(80.7 \%$ ) answered that percentage of the project success level was more than $50 \%$ and $33.9 \%$ of the respondents stated that this percentage was more than $75 \%$. Furthermore, there are the two results of the inferential analyses, including the measurement and structural model assessments.

First, the measurement model assessments. 1) Indicator reliability was evaluated using the values of the indicator loadings with loading of 0.7 or above [32-36]. Referred to [31] who cited [32], SVQ6 was dropped because its loading was less than 0.4. 2) Internal consistency realibility was evaluated using composite realibility (CR) with the threshold value 0.7 [32-37]. Although, several studies, e.g. [31] indicated the use of Cronbach's alpha (CA) in this assessment, we considered to use CR because CA tends to severely underestimate the internal consistency reliability of variable [39] especially its assumption that all indicators within the variable have the same range and meaning, equally reliable, and without considering their item loadings [38-39]. 3) Convergent validity was evaluated using AVE with the acceptable threshold of 0.5 [3236]. Table 3 shows the result which it presented that all of the variables have AVE in above the used threshold value. 4) Discriminant validity was evaluated through analysis of cross-loading [32-36] and deleted SYQ2, USF1, and PCS5 because their loadings was under than their cross-loadings (Table 3). Similar to studies, e.g. [31] and [40] who referred to the definition that is the extent to which a given variable is different from the others [40], the squared AVE of the variables were also used in this assessment. Table 4 shows that the squared AVE of the variables was greater that their correlation variances. In short, the results of the above mentioned assessments present that the measurement items of this study demonstrate a good psychometric properties, especially for measuring the structural model assessments [33-36] respectively.

Table 1. Respondent profiles

\begin{tabular}{ccc}
\hline Measures & Items & $\%$ \\
\hline Education & High school & 8.1 \\
& Diploma & - \\
& Bachelor & 27.4 \\
& Master & 56.5 \\
IS Project & Doctor & 8.1 \\
Experience & 2-5 years & 35.5 \\
& 5-10 years & 16.1 \\
& >10 years & 40.3 \\
Position & Top Manager & 8.1 \\
& Business unit manager & 27.4 \\
& IS/IT unit manager & 6.5 \\
& Project manager & 6.5 \\
& Project team member & 58.1 \\
\hline
\end{tabular}

Table 2. IS project profiles

\begin{tabular}{ccc}
\hline Measures & Items & $\%$ \\
\hline Development & Operational requirements & 41.9 \\
goals & Managerial requirements & 16.1 \\
& Strategic requirements & 17.7 \\
& Operational and managerial requirements & 6.5 \\
& Operational \& strategic requirements & 8.1 \\
Ownership of & Operational, managerial \& strategic requirements & 9.7 \\
IS strategic & Available & 71.0 \\
plan & Not available & 6.5 \\
IS development & Unknown & 22.6 \\
strategy & $100 \%$ buying & 3.2 \\
& Majority buying & 27.4 \\
& $50-50$ & 21.0 \\
Funding & Majority internal development & 43.5 \\
& $100 \%$ internal development & 4.8 \\
& $100 \%$ internal funding & 30.6 \\
& Majority internal funding & 38.7 \\
Success Level & $50-50$ & 12.9 \\
& Majority external funding & 12.9 \\
& $100 \%$ external funding & 4.8 \\
& $<25 \%$ & 6.5 \\
& $25-50 \%$ & 12.9 \\
& $50-75 \%$ & 36.8 \\
\hline
\end{tabular}

Second, the structural model assessments. 1) The coefficient of determination $\left(R^{2}\right)$ was evaluated with values of approximately 0.670 are considered substantial, values around 0.333 moderate, and values around 0.190 weak [33-36]. All other variables together substantially explained $55.8 \%$ of the variance in 
PSC. While, INQ, SYQ, and SVQ together moderately expressed $42.5 \%$ of the SYU variance and substantially described $69.7 \%$ of the USF variance. 2) The path coefficients $(\beta)$ were evaluated with the above value of 0.1 to account for a certain impact within the model [33-36]. Figure 3 and Table 5 show that eight of $12 \beta \mathrm{s}$ were statistically significant and the highest number of $\beta$ s was between SVQ and PSC (0.416). 3 ) The effect size $\left(f^{2}\right)$ was evaluated using values of appropriately $0.020,0.150$, or 0.350 indicate the predictor variable's low, medium, or large effect in the structural model. The result presents that two of 12 paths have only the medium effects and the others have smaller effects. 4) Structural path significance in bootstrapping was evaluated using critical $t$-value (1.650) for two-tailed test with significance level $=10$ percent [34] to validate the hypotheses [33-36]. Table 5 shows that four of 12 hypotheses are accepted and the others are rejected. In brief, results of the structural model assessments above present consistencies and inconsistencies with the previous studies.

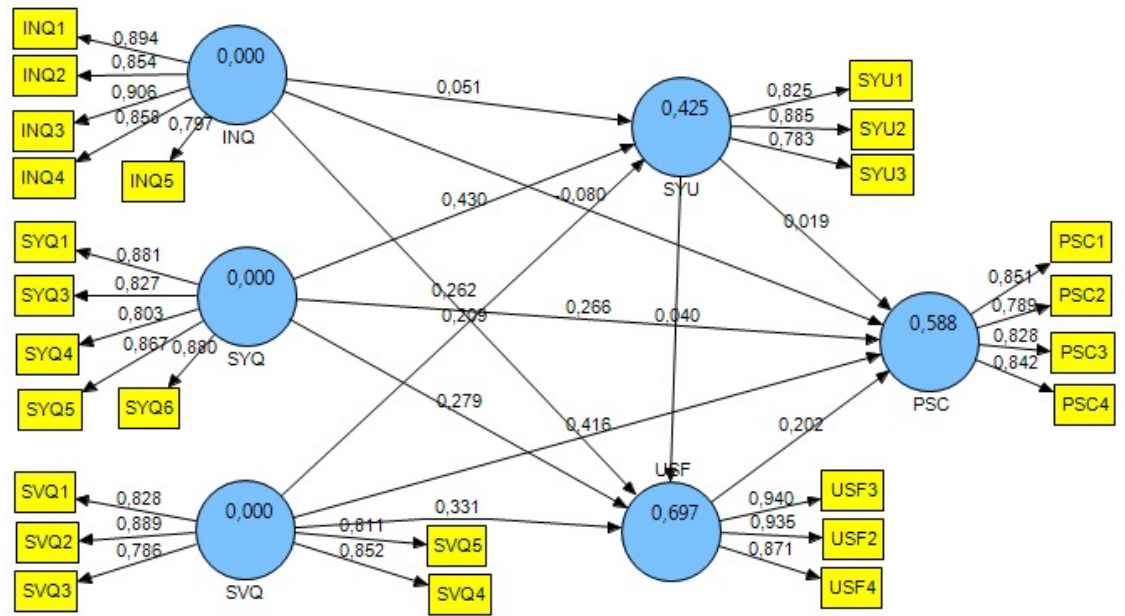

Figure 3. The SmartPLS results of the research model

Table 3. The measurement model assessments

\begin{tabular}{|c|c|c|c|c|c|c|c|c|c|c|}
\hline \multirow{2}{*}{ Ref. } & \multirow{2}{*}{ Indicators } & \multirow{2}{*}{$\mathrm{OL}$} & \multicolumn{6}{|c|}{ Cross-loadings } & \multirow{2}{*}{$\mathrm{CR}$} & \multirow{2}{*}{ AVE } \\
\hline & & & INQ & PSC & SVQ & SYQ & SYU & USF & & \\
\hline [7] & Accuracy (INQ1) & 0.894 & 0.894 & 0.597 & 0.712 & 0.693 & 0.574 & 0.715 & 0.936 & 0.744 \\
\hline [7] & Timeliness (INQ2) & 0.854 & 0.854 & 0.573 & 0.716 & 0.708 & 0.623 & 0.666 & & \\
\hline [7] & Completeness (INQ3) & 0.906 & 0.906 & 0.477 & 0.660 & 0.725 & 0.436 & 0.631 & & \\
\hline [7] & Relevance (INQ4) & 0.858 & 0.858 & 0.542 & 0.626 & 0.716 & 0.363 & 0.699 & & \\
\hline [7] & Consistency (INQ5) & 0.797 & 0.797 & 0.456 & 0.531 & 0.699 & 0.383 & 0.568 & & \\
\hline [7] & Resources savings (PSC1) & 0.851 & 0.589 & 0.851 & 0.698 & 0.654 & 0.526 & 0.612 & 0.897 & 0.685 \\
\hline [23] & Managerial effectiveness (PSC2) & 0.789 & 0.425 & 0.789 & 0.486 & 0.526 & 0.229 & 0.459 & & \\
\hline [23] & Productivity improvement (PSC3) & 0.828 & 0.459 & 0.828 & 0.533 & 0.498 & 0.427 & 0.559 & & \\
\hline [24] & Customer satisfaction (PSC4) & 0.842 & 0.549 & 0.842 & 0.671 & 0.611 & 0.434 & 0.603 & & \\
\hline [25] & Competitive advantage (PSC5) & Deleted & & & & & & & & \\
\hline [7] & Assurance (SVQ1) & 0.828 & 0.646 & 0.597 & 0.828 & 0.641 & 0.432 & 0.583 & 0.919 & 0.696 \\
\hline [7] & Empathy (SVQ2) & 0.889 & 0.705 & 0.686 & 0.889 & 0.700 & 0.513 & 0.636 & & \\
\hline [7] & Responsiveness (SVQ3) & 0.786 & 0.642 & 0.642 & 0.786 & 0.751 & 0.561 & 0.714 & & \\
\hline [26] & Flexibility (SVQ4) & 0.852 & 0.561 & 0.491 & 0.852 & 0.613 & 0.491 & 0.614 & & \\
\hline [26] & Interpersonal quality (SVQ5) & 0.811 & 0.596 & 0.614 & 0.811 & 0.562 & 0.434 & 0.661 & & \\
\hline [27] & Security (SVQ6) & Deleted & & & & & & & & \\
\hline [7] & Ease-of-use (SYQ1) & 0.881 & 0.699 & 0.625 & 0.621 & 0.881 & 0.486 & 0.642 & 0.930 & 0.726 \\
\hline [7] & Reliability (SYQ2) & Deleted & & & & & & & & \\
\hline [28] & Flexibility (SYQ3) & 0.827 & 0.668 & 0.549 & 0.658 & 0.827 & 0.641 & 0.678 & & \\
\hline [7] & Functionality (SYQ4) & 0.803 & 0.687 & 0.580 & 0.612 & 0.803 & 0.493 & 0.569 & & \\
\hline [8] & Maintainability (SYQ5) & 0.867 & 0.761 & 0.614 & 0.774 & 0.867 & 0.588 & 0.711 & & \\
\hline [7] & Response time (SYQ6) & 0.880 & 0.673 & 0.608 & 0.686 & 0.880 & 0.494 & 0.714 & & \\
\hline [7] & Nature of use (SYU1) & 0.825 & 0.401 & 0.415 & 0.380 & 0.424 & 0.825 & 0.403 & 0.871 & 0.692 \\
\hline [7] & Extent of use (SYU2) & 0.885 & 0.569 & 0.451 & 0.590 & 0.646 & 0.885 & 0.547 & & \\
\hline [29] & Intensity of use (SYU3) & 0.783 & 0.408 & 0.380 & 0.468 & 0.489 & 0.783 & 0.426 & & \\
\hline [30] & Adequacy (USF1) & Deleted & & & & & & & & \\
\hline [30] & Effectiveness (USF2) & 0.935 & 0.677 & 0.603 & 0.705 & 0.669 & 0.499 & 0.935 & 0.940 & 0.839 \\
\hline [30] & Efficiency (USF3) & 0.940 & 0.714 & 0.582 & 0.683 & 0.708 & 0.498 & 0.940 & & \\
\hline [23] & Overall satisfaction (USF4) & 0.871 & 0.704 & 0.677 & 0.731 & 0.759 & 0.534 & 0.871 & & \\
\hline
\end{tabular}


Table 4. The squared AVE of the variables

\begin{tabular}{ccccccc}
\hline & INQ & PSC & SVQ & SYQ & SYU & USF \\
\hline INQ & $\mathbf{0 , 8 6 3}$ & & & & & \\
PSC & 0,619 & $\mathbf{0 , 8 2 8}$ & & & & \\
SVQ & 0,759 & 0,732 & $\mathbf{0 , 8 3 4}$ & & & \\
SYQ & 0,819 & 0,698 & 0,789 & $\mathbf{0 , 8 5 2}$ & & \\
SYU & 0,562 & 0,501 & 0,587 & 0,637 & $\mathbf{0 , 8 3 2}$ & \\
USF & 0,765 & 0,681 & 0,774 & 0,780 & 0,559 & $\mathbf{0 , 9 1 6}$ \\
\hline
\end{tabular}

Tabel 5. The structural model assessments

\begin{tabular}{lcccccc}
\hline Hypotheses & $\beta$ & $f^{2}$ & $t$-test & \multicolumn{3}{c}{ Analyses } \\
& & & $\beta$ & $f^{2}$ & $t$-test * \\
\hline INQ $\rightarrow$ PSC & $-0,080$ & 0,005 & 0,446 & insignificant & small & Rejected \\
INQ $\rightarrow$ SYU & 0,051 & 0,002 & 0,224 & insignificant & small & Rejected \\
INQ $\rightarrow$ USF & 0,262 & 0,065 & 1,900 & significant & small & Accepted \\
SVQ $\rightarrow$ PSC & 0,416 & 0,128 & 2,185 & significant & Medium & Accepted \\
SVQ $\rightarrow$ SYU & 0,209 & 0,026 & 1,016 & significant & small & Rejected \\
SVQ $\rightarrow$ USF & 0,331 & 0,118 & 1,963 & significant & Medium & Accepted \\
SYQ $\rightarrow$ PSC & 0,266 & 0,036 & 1,164 & significant & small & Rejected \\
SYQ $\rightarrow$ SYU & 0,430 & 0,085 & 1,865 & significant & small & Accepted \\
SYQ $\rightarrow$ USF & 0,279 & 0,066 & 1,462 & significant & small & Rejected \\
SYU $\rightarrow$ PSC & 0,019 & $-0,003$ & 0,139 & insignificant & - & Rejected \\
SYU $\rightarrow$ USF & 0,040 & 0,002 & 0,310 & insignificant & small & Rejected \\
USF $\rightarrow$ PSC & 0,202 & 0,024 & 1,143 & significant & small & Rejected \\
\hline * Two-tailed at $p<0.10$ & & & &
\end{tabular}

\section{DISCUSSIONS}

According to the results of the analysis stage and the two research questions, two main discussion points of the study are:

First, although the performance of the IS projects was indicated especially to fulfil the operational requirements with the internal developers and fundings, it was carried out based on the developed IS strategic plan. Therefore, it is not suspringly if the level of the success is majority successful. As it was indicated by most of the respondents $(80.7 \%)$ who answered that percentage of the project success level was more than $50 \%$. Moreover, $33.9 \%$ of the respondents stated that this percentage was more than $75 \%$. The gradual objective attainments from the operational to the strategic objectives based on the IS strategic plan were in line with the previous project performance studies [11-14] especially which described that the success of a project can be indicated through the project management and the product utilization successes.

Second, there are three issues in regard to the findings of this study: 1) The findings present statistically that INQ and SYU affect insignificantly PSC as this was indicated by the path significance assessment (Table 5). It is inconsistent with the results of the previous meta-analysis studies related to D\&M IS success model, e.g. [8-10] and project success theories [11-14]. For instance, [8] described that most of the paths between both INQ and SYU (system use) and PSC (net benefits) in both individual and organizational levels of analyses are the significant paths in moderate support. In this study, this might unsupported by the collected data or this might be the trend of the project implementation. 2) Majority of the effects of the five examined factors toward PSC (10 of the 13 paths) present statistically the small effects, only two paths $(\mathrm{SVQ} \rightarrow \mathrm{USF}$ and SVQ $\rightarrow \mathrm{PSC}$ ) which have statistically effects in the medium size, and even one path $(\mathrm{SYU} \rightarrow \mathrm{PSC}$ ) does not present effect statistically. These findings are inconsistent with the previous studies [7-14]. Similar to the first issue, this might unsupported by the collected data or portrait of the project performance trends. 3) It is surprising to notice that only four of the 13 hypotheses are statistically accepted in the hypothesis validation (Table 5). In regard to the selected theories and model which were used to develop the research model, this is an inconsistency, especially with the project success theories [12-17] which described that the project success should be supported by the two aspects, i.e. the project management (INQ, SYQ, and SVQ) and the product utilization (SYU and USF), not only one of the both aspects. Similarly, this might unsupported by the collected data or portrait of the project performance trends which its implementation was only focused to the project management successes.

On the other hand, several limitations were inherent within this study despite efforts to guard against it. First, the findings of this study should not be generalized for another institution because the data is only from the sampled institution. Data from the other sources may be different from what was reported and discussed herein. Second, this study involved the selected stakeholder types. Although involvement of these key informants [20-21] were conducted to reach comprehensiveness of the findings, it might also be differ somewhat on certain issues presented in the instruments. Accordingly, we didn't control for this possibility of such happening in this study. Third, the subsequent researches can put this current findings and its conceptualization especially reconsidering the above mentioned limitations could be addressed in order to improve the validity of the findings. As presented in the analysis stage, the factors considered in this study only explained $58.8 \%$ their variances. Therefore, the other relevant factors and issues can be incorporated into the next research model to increase the predictive power. For example, in light of the fact that INQ and SYU were not found to affect significantly the IS project success in the sampled institution. It is reasonable to suggest that by adding attentions in these factors and considering to incorporate the other relevant factors, e.g. environmental context $[17,43,44]$ may be encourage level of the project success attainment. 


\section{CONCLUSION}

The study presents relevance of the D\&M model for its adoption and adaptation with the selected project success theories. Besides, some findings are consistent with the findings of the previous studies, the current findings are also presented several inconsistencies, especially related to the information quality and system use factors. However, we conducted indeed some efforts to design and perform this study, several limitations are still inherent within the study. Accordingly, the subsequent explanatory researches are needed to explain why information quality and system is affected insignificantly the project success as it is also needed to give the adequate attention to the foregoing significant factors in order to improve the attainment of the project success in the sampled institution. Therefore, we recommend that the institution, researchers, and practitioners will be stand to benefit from the information provided in this study and it is hoped that the future researches will build upon the findings reported herein as efforts to attain the IS project success especially in the sampled institution.

\section{ACKNOWLEDGEMENTS}

This work was supported by the Research-Based National Publication Program No. Un.01/KPA/182/2014. The Center of Research and Publication, Syarif Hidayatullah State Islamic University Jakarta, Indonesia.

\section{REFERENCES}

[1] G. Kirkup and A. Kirkwood. "Information and communications technologies (ICTs) in higher education teaching: A tale of gradualism rather than revolution". Learning, Media and Technology. vol. 30 (2), pp. 185-199, 2005.

[2] C.J. Patel, et al. "The effects of information and communication technologies (ICTs) on higher education: From objectivism to social constructivism". Int' of Vocational and Technical Education. vol. 3 (5), pp. 113-120, 2011.

[3] Y.E. Chan and B.H. Reich. "IT alignment: what have we learned?" Journal of IT. vol. 22 (4), pp. 297-315, 2007.

[4] A. Subiyakto and A.R. Ahlan. "A coherent framework for understanding critical success factors of ICT project environment”. Proceeding of ICRIIS'13. pp. 342-347, IEEE, 2013.

[5] X. Xu, et al. "IT infrastructure capabilities and IT project success: a development team perspective". Information Technology and Management. vol. 11 (3), pp. 123-142, 2010.

[6] The Standish Group International. "CHAOS Manifesto 2013: Think big, act small”. West Yarmouth, MA, 2003.

[7] W.H. DeLone and E. McLean. "The DeLone and McLean model of information systems success: a ten-year update". Journal of Management Information Systems. vol. 19 (4), pp. 9-30, 2003.

[8] S. Petter, et al. "Measuring information systems success: models, dimensions, measures, and interrelationships". European Journal of Information Systems. vol. 17, pp. 236-263, 2008.

[9] D.W.I.N. Urbach, et al. "The state of research on information systems success". Business \& Information Systems Engineering. vol. 1 (4), pp. 315-325, 2009.

[10] N. Urbach and B. Müller. "The updated DeLone and McLean model of information systems success". Information Systems Theory, New York: Springer. pp. 1-18, 2012.

[11] A. De Wit. "Measurement of project success". International Journal of Project Management (IJPM). vol. 6, pp. 164-170, 1988.

[12] Wateridge J. "How can IS/IT projects be measured for success". IJPM. vol. (16)1, pp. 59-63, 1998.

[13] T. Van Aken. "De weg naar project succes: Eerder via werkstijl dan instrumenten". De Tijdstroom. p. 411, 1996 cited in [4]

[14] K. Jugdev and R. MÜller. "A retrospective look at our evolving understanding of project success". Project Management Journal. vol. 36, pp. 19-31, 2005.

[15] A. Belout and C. Gauvreau. "Factors influencing project success: the impact of human resource management". IJPM. vol. 22 (1), pp. 1-11, 2004.

[16] G.P. Prabhakar. "Projects and their management: a literature review". International Journal of Business and Management. vol. 3 (8), P3, 2008.

[17] E.M. Howsawi, et al. "Understanding project success: the four-level project success framework". Proceeding of IEEE-IEEM, Singapore. pp. 620-624, 2011.

[18] R.O. Mason. "Measuring information output: a communication systems approach". Information Management. vol. 1 (5), pp. 219-234, 1978, cited in [7].

[19] C.E. Shannon and W. Weaver. "The mathematical theory of communication". Illinois: University of Illinois Press. 1949, cited in [7].

[20] J.W. Creswell. "Research design: Qualitative, quantitative, and mixed methods approaches". Sage Publications. 2013.

[21] C. Marshall and G.B. Rossman. "Designing qualitative research". Sage Publications. 2010.

[22] M.C. Kaptein, et al. "Powerful and consistent analysis of likert-type ratingscales". Proceedings of the SIGCHI Conference on Human Factors in Computing Systems, ACM. pp. 2391-2394, 2010

[23] G.G. Gable, et al. "Re-conceptualizing information system success: THE IS-impact measurement model". Journal of the Association for Information Systems. vol. 97, pp. 377-408, 2008.

[24] R. Sabherwal. "The relationship between information system planning sophistication and information system success: an empirical assessment”. Decision Sciences. vol. 301, pp. 137-167, 1999. 
[25] H. Almutairi and G.H. Subramanian. "An empirical application of the Delone and McLean Model in the Kuwaiti private sector". Journal of Computer Information Systems. vol. 453, pp. 113-122, 2005.

[26] J.C.J. Chang and W.R. King. "Measuring the performance of information systems: A functional scorecard". Journal of Management Information Systems. vol. 221, pp. 85-115, 2005.

[27] T. Xu, et al. "Security interaction of web services in heterogeneous platforms". TELKOMNIKA Indonesian Journal of Electrical Engineering. vol. 12 (4), 2014.

[28] J. Iivari. "An empirical test of DeLone-McLean model of information systems success". ACM Sigmis Database. vol. 36(2), pp. 8-27, 2005.

[29] Y.S. Wang. "Assessing e-commerce systems success: a respecification and validation of the DeLone and McLean model of IS success". Information Systems Journal. vol. 18, pp. 529-557, 2008.

[30] P. Seddon and M.Y. Kiew. "A partial test and development of DeLone and McLean's Model of IS success". Australasian Journal of Information Systems. vol. 4 (1), pp. 90-109, 2007.

[31] A.H. Memon and I.A. Rahman. "Analysis of Cost Overrun Factors for Small Scale Construction Projects in Malaysia Using PLS-SEM Method”. Modern Applied Science. vol. 7 (8), p78, 2013.

[32] J. Hulland. "Use of partial least squares (PLS) in strategic management research: a review of four recent studies". Strategic Management Journal. vol. 20 (2), pp. 195-204, 1999.

[33] N. Urbach and F. Ahlemann. "Structural equation modelling in information systems research using partial least squares". Journal of Information Technology Theory and Application. vol. 11 (2), pp. 5-40, 2010.

[34] J.F. Hair, et al. "PLS-SEM: Indeed a silver bullet". The Journal of Marketing Theory and Practice. vol. 19 (2), pp. 139-152, 2011.

[35] J.F. Hair, et al. "An assessment of the use of partial least squares structural equation modelling in marketing research". Journal of the Academy of Marketing Science. vol. 40 (3), pp. 414-433, 2012.

[36] K.K.K. Wong. "Partial Least Squares Structural Equation Modelling (PLS-SEM) Techniques Using Smart PLS". Marketing Bulletin. vol. 24, pp. 1-32, 2013.

[37] J.C. Nunnally and I.H. Bernstein. "Psychometric Theory". New York: McGraw-Hill. 1994.

[38] L.J. Cronbach. "Coefficient alpha and the internal structure of tests". Psychometrika. vol. 16 (3), pp. 297-334, 1951.

[39] W.W. Chin. "The partial least squares approach to structural equation modelling". Modern Methods for Business Research. vol. 295 (2), pp. 295-336, 1998.

[40] P. Ifinedo. "Internet/E-Business Technologies Acceptance in Canada's SMEs: Focus on Organizational and Environmental Factors". in E-Business-Applications and Global Acceptance. Rijeka: InTech, Croatia. 2012.

[41] C. Fornell and D.F. Larcker. "Evaluating structural equation models with unobservable variables and measurement error". Journal of Marketing Research. vol. 18 (1), pp. 39-50, 1981.

[42] G. Fitzgerald and N.L. Russo. "The turnaround of the London ambulance service computer-aided dispatch system (LASCAD)". EJIS. vol. 14 (3), pp. 244-257, 2005.

[43] L. McLeod and S.G. MacDonell. "Factors that affect software systems development project outcomes: a survey of research". ACM Computing Surveys. vol. 43 (4), pp. 24-56, 2011.

[44] A. Subiyakto, et al. "An Alternative Method for Determining Critical Success Factors of Information System Project”. TELKOMNIKA Telecommunication, Computing, Electronics and Control. Vol. 12 (3), pp. 665-674, 2014.

\section{BIOGRAPHIES OF AUTHORS}

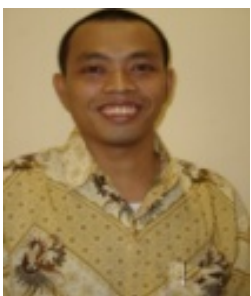

A'ang Subiyakto is a lecturer in the Department of IS at the Syarif Hidayatullah State Islamic University Jakarta, Indonesia. He graduated from the bachelor and master degrees in IS and has been studying his $\mathrm{Ph} . \mathrm{D}$ in IT at the Department of IS, the International Islamic University Malaysia, Malaysia. His research topic is about IT/IS project management, especially in the project performance measurement.

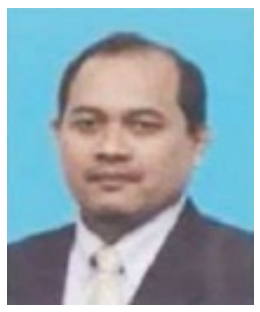

Abd. Rahman Ahlan is an Associate Professor in the Department of IS at the International Islamic University Malaysia, Malaysia. He graduated with his $\mathrm{PhD}$ in IS at the Cardiff University, MSc in IT at the University of Warwick, UK and BBA at the International Islamic University Malaysia. His research topics are around IT/IS implementation issues and project management with many international publications in reputed publishers. 
Mira Kartiwi is an Associate Professor in the Department of IS at the International Islamic University Malaysia. She completed her Ph.D, MIS, B. Com in Business IS at the University of Wollongong, Australia. Her research topics are around database, data Mining, e-commerce, and ehealth with many international publications in reputed publishers

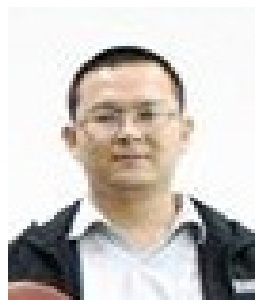

Husni Teja Sukmana is a lecture in the Departement of Informatics Engineering, the Syarif Hidayatullah State Islamic University Jakarta, Indonesia. He graduated from master and doctoral degree in Computer Science at the Sunmoon University, South Korea. His previous research topics are related to Embedded System, however, he becomes interested in researches related to IT service management. 